\title{
NOTE ON THE COMPOSITION OF A FLUID OBTAINED FROM THE UDDERS OF VIRGIN HEIFERS
}

\author{
By HeRBert ERNEST WOODMAN, Ph.D., D.Sc., \\ AND JOHN HAMMOND, M.A. \\ (From the Institute for the Study of Animal Nutrition, \\ School of Agriculture, Cambridge University.)
}

THE secretion of milk by the mammary glands normally follows a period of pregnancy, but numerous cases have been cited in the literature of secretion which takes place in animals that have never borne young. Non-pregnant bitches frequently secrete milk several weeks after oestrus (1), and a secretion, apparently similar to milk, takes place after pseudo-pregnancy in rabbits(2). No quantitative analyses have been made of these secretions to show whether they possess the characteristics of true milk or colostrum.

The origin and significance of colostrum itself, as distinct from milk, is also in doubt, and its formation has variously been attributed to: (1) The break up of the central cells of the alveolus, or as a result of their initial activities; (2) The filtration of lymphatic secretion through the walls of the alveoli mixing with the milk formed by the cells. Recent work on the proteins of colostrum(3) has shown that although the caseinogen and albumin must be elaborated by the mammary gland, yet the globulin, which is present in large amount in the colostral secretion, is in every respect identical with the globulin of blood serum.

There also exists the possibility that colostrum results from the partial absorption of the more diffusible milk constituents, the secretion of which has been taking place to a small extent some time previously.

It was therefore of considerable interest to find, during a study which is being made by one of us (J. H.) of the development of the udder of the cow, that the galactophorous sinuses and ducts of virgin heifers of some $1 \frac{1}{2}$ to $2 \frac{1}{2}$ years of age contained very frequently a fluid which could often be expressed from the nipples in quite considerable amounts. The object of the present work was to investigate the composition of the secretion and its possible relation to colostrum and to milk.

It has been suggested by several writers (4) that the mammary gland Journ. of Agric. Sci. xn. 
undergoes a cycle correlated with that existing in the ovaries and culminating at oestrus by a swelling of the mammary gland. Since heifers have periodic corpora lutea and a well-marked ovarian cycle, it might be supposed that the former acted in much the same way as those of pseudo-pregnant rabbits, but to a smaller extent. It was not unreasonable therefore to suppose that this fluid was secreted just before the period of oestrus in heifers, but attempts to prove this so far have been without success. The fluid can be drawn off from the udder at any period of the cycle, and the amount varies considerably according to the individual. In animals killed at various periods of the oestrous cycle, there was an indication that more existed just before the oestrous period than at any other time. But individual cases were also found which did not show this behaviour.

The secretion of milk has been attributed to the removal of the stimulus which caused the mammary gland to develop. Thus LaneClaypon and Starling(5) and others have attributed this action to the foetus, but Marshall and Hammond(2) found that the corpus luteum caused the growth of the mammary gland in the rabbit, and that milk was produced whenever the gland had developed to a sufficient extent.

The removal of the causative stimulus in heifers cannot, however, be the cause of the secretion, as the fluid has been found in the udders of previously virgin heifers pregnant 3-4 months, at a time when the corpus luteum is still large and active.

The problem thus presented itself: Is the secretion similar to that of colostrum and milk, resulting from the activity of the cells of the alveoli, or is it merely an exudation of lymph filling up the galactophorous sinuses, which have been formed by the development of the mammary gland? If the latter hypothesis be found correct, then at what stage in the development of the mammary gland do the typical constituents of milk first appear?

\section{Chemical investigation of the flutd.}

In all, four samples of the fluid were examined. The first two samples were obtained from heifers which had never been served, whilst the third and fourth samples were taken from the udders of the heifers during the first three weeks of pregnancy.

The amount of fluid was only small, each heifer contributing on an average about 7 c.c. to the supply. The liquid was slightly opaque in appearance, though not possessing the dense opaqueness of milk. A slight sediment settled out on standing, but the fluid passed fairly 
readily through a filter paper, the filtrate then being almost clear and possessing the appearance of a protein solution. It was slightly viscous, gave a foam on shaking and did not show the amphoteric reaction of fresh milk, but was very faintly alkaline to both litmus and phenolphthalein.

A preliminary investigation of the first two samples was carried out as follows. A small volume of the fluid was diluted with distilled water and one drop of acetic acid was added. On shaking, a white flocculent precipitate settled out in a manner characteristic of the separation of caseinogen from milk by this method. This was filtered off and was shown to be a protein by the usual tests. Furthermore, it answered to all the characteristic tests for caseinogen. (1) It was insoluble in water but dissolved readily in dilute soda and in lime-water and was reprecipitated by the addition of a drop of acetic acid. (2) When fused with a mixture of $\mathrm{K}_{2} \mathrm{CO}_{3}$ and $\mathrm{KNO}_{3}$, the solution obtained on extracting the residue with water gave a strong phosphate test with nitric acid and ammonium molybdate. (3) The freshly precipitated protein was completely soluble in excess of acetic acid.

Further tests were made in order to ensure that the substance was not a nucleoprotein, which class of bodies gives most of the general reactions of the phosphoproteins. The presence of nucleoproteins in such a fluid would, moreover, not be at all surprising, especially if it resulted from the filtration of lymph through the walls of the alveoli. That the protein was caseinogen, however, and not a nucleoprotein was shown by: (1) The readiness with which it split off its phosphorus as inorganic phosphate by mild alkaline hydrolysis. Under these conditions, nucleoproteins do not yield phosphoric acid, the phosphorus remaining bound up in the nucleic acid group (6). (2) The behaviour of the fluid towards rennet. To 5 c.c. of the fluid were added 2 c.c. rennet extract. On placing in a bath at $40^{\circ}$, only a slight turbidity resulted after two minutes. On the further addition of two drops of calcium chloride solution to the mixture, however, the turbidity increased and a curdy precipitate settled out. A clear mixture of 5 c.c. fluid, 2 c.c. rennet extract and 1 c.c. calcium chloride solution was placed in a bath at $40^{\circ}$. In a few seconds, a turbidity spread throughout the liquid, followed by a rapid separation of curdy precipitate. This behaviour was consistent with the presence of caseinogen in the fluid, the rennet producing, in the presence of calcium salts, a precipitate of insoluble calcium caseate from the soluble calcium caseinogate. (3) The absence of any insoluble nuclein residue when the protein was submitted to peptic digestion. 


\section{Fluid obtained from Udders of Virgin Heifers}

The filtrate remaining after separation of the caseinogen was heated a short time in boiling water. This caused coagulation and the substance which separated in this manner was shown to be protein by the ordinary tests. The nature of the coagulable proteins was investigated in the following manner. After separating the caseinogen from another portion of the fluid, the clear filtrate was made exactly neutral by means of $N / 10 \mathrm{NaOH}$ and was then saturated with magnesium sulphate. The protein which was salted out by this process was filtered off and redissolved in water. On saturating this solution with magnesium sulphate, the protein was again thrown out. It possessed therefore the characteristics of a globulin.

The filtrate from the globulin was next acidified with acetic acid. A further precipitate of protein was obtained, its mode of isolation proving it to be an albumin. As far as it was possible to judge from the tests, the fluid contained rather more globulin than albumin.

The liquid remaining after removal of caseinogen by acetic acid and albumin and globulin by coagulation still answered to the biuret test and gave an appreciable precipitate with tannic acid. It still contained nitrogenous bodies of a simpler type, amongst which was a proteose, since a further precipitate was obtained on saturating the liquid with ammonium sulphate. The existence of non-protein nitrogen in the fluid was borne out by subsequent analysis.

The fluid, after removal of proteins, was found to exert a slight reducing action when boiled for some time with Fehling's solution. The osazone, which was only obtained in small amount and with difficulty, had the characteristic appearance of lactosazone under the microscope. A sample of milk, tested similarly, showed ready and copious reduction of Fehling's solution and gave a good yield of lactosazone without difficulty. In all the samples of fluid examined, it was only possible to demonstrate the presence of lactose in small amounts.

A preliminary extraction of the fluid with ether showed it to contain a small amount of fat. Sample 4 was found, by the Paper Coil method, to contain about 0.6 per cent. of a solid yellow fat. This was saponified by boiling a short time with caustic soda. After acidifying, extracting with ether and allowing the solvent to evaporate, the residue possessed the characteristic odour of butyric acid. It followed that the fat in the fluid was the product of mammary synthesis.

The fluid did not contain any detectable amount of mucin, since this would have shown as gelatinous strands on the addition of acetic acid. The precipitate thus obtained was, however, perfectly flocculent 
and was, moreover, completely dissolved by the addition of excess of acetic acid. Mucin remains undissolved under these conditions. The perfectly flocculent character of the precipitate obtained on adding alcohol to the fluid and stirring precluded the possibility of the presence of pseudo-mucins in the fluid. No other glucoproteins were found in the fluid, since on hydrolysing the total protein with hydrochloric acid, no reducing sugars were formed.

The main constituents of the fluid were, therefore, caseinogen, globulin and albumin, with traces of fat, lactose and simpler nitrogenous substances (proteoses). In view of the obvious importance of the fluid in its relationship to the ultimate colostrum and milk secretions, it was advisable, as far as was possible, to conduct a quantitative enquiry. Unfortunately, no one sample obtained was large enough to permit of a complete analysis being carried out on it. The following figures were', however, obtained and give some idea of the quantitative composition of the fluid. The data for milk and a sample of colostrum containing roughly the same amount of protein are appended for comparison.

Samples 1 and 2.

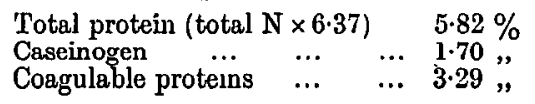

Sample 3.

\begin{tabular}{|c|c|c|c|c|c|}
\hline \multirow{2}{*}{\multicolumn{3}{|c|}{ Total protein $(\mathrm{N} \times 6.37)$}} & \multirow{2}{*}{ Fluid } & Colostrum $^{1}$ & Milk $^{2}$ \\
\hline & & & & $6 \cdot 18 \%$ & - \\
\hline Caseinogen & $\ldots$ & & 2.50, & 3.25, & $2.90 \%$ \\
\hline & $\cdots$ & $\cdots$ & $2 \cdot 28 "$ & $1.97 "$ & Trace \\
\hline & & $\ldots$ & 1.00, & 0.70, & 0.60, \\
\hline & & & iple & & \\
\hline & & & & & Colostrum \\
\hline $\begin{array}{l}\text { ific grav } \\
\text { I solids }\end{array}$ & & $\ldots$ & & $\begin{array}{c}1.032 \\
12.25 \%\end{array}$ & $\begin{array}{r}1 \cdot 0 \\
14 \cdot 19\end{array}$ \\
\hline . & $\ldots$ & $\ldots$ & & & 0.96 \\
\hline Fat? & $\ldots$ & $\ldots$ & 0.6 & $3 \cdot 40$, & $4.21 "$ \\
\hline
\end{tabular}

1 Crowther and Raistrick, Bioch. J., 10, 435, 1916. The sample represented the fourth milking after parturition.

2 Fleischmann.

3 The globulin was separated from the liquid, remaining after removal of caseinogen with acetic acid, by neutralising with $\mathrm{N} / 10 \mathrm{NaOH}$ and saturating with magnesium sulphate. After filtering, the precipitate was well washed with saturated magnesium sulphate solution and its amount estimated by the Kjeldahl method. The albumin was isolated from the filtrate by acidifying with acetic acid and standing in boiling water for a short time.

- Fleischmann.

5 Eugling. Sample taken 48 hours from parturition and contained about $6 \%$ protein.

- The ash gave the reactions for phosphate and calcium.

7 Paper Coil method. 


\section{Fluid obtained from Udder's of Virgin Heifers}

\section{Conclusions.}

A secretion has been found to occur in small amount in the udders of virgin heifers which contains the characteristic proteins of colostrum, together with slight amounts of fat, lactose and proteose. It follows that the initiation of mammary gland activity in the dairy cow is not necessarily dependent on pregnancy, but may be associated with the occurrence of the oestrous cycle. The processes which result in the elaborations of proteins would appear to be the most active in this early stage of the gland's activity, sunce only small amounts of fat and sugar seem to be formed.

The fluid bears, on account of its globulin content, a closer relation to colostrum than to milk. The question arises as to whether the secretion continues to accumulate throughout pregnancy, or whether it undergoes gradual reabsorption. It is hoped to gain information on this and other points by following the changes in the yield and composition of the fluid at regular periods throughout the progress of pregnancy.

\section{REFERENCES.}

(1) Marshall and Halnan. Proc. Royal Soc. B., 89, 1917.

(2) Hammond and Marshall. Proc. Royal Soc. B., 87, 1914.

(3) Woodman. Bioch. J., 15, 187, 1921.

(4) Marshall. The Physiology of Reproduction, London, 1910.

(5) Lane-Claypon and Staritia. Proc. Royal Soc. B., 77, 1906.

(6) Pummer. Practical Organic and Bio-Chemistry, p. 466.

(Received January 13th, 1922.) 